DOI 10.15826/B978-5-7996-2935-9.41

WASP-12 b И WASP-4 b: ПЛАНЕТЫ, СВАЛИВАЮЩИЕСЯ НА СВОЮ ЗВЕЗДУ?

Р. В. Балуев ${ }^{1,2}$, Е. Н. Соков ${ }^{1,2}$, И. А. Сокова ${ }^{1,2}$, В. Ш. Шайдулин ${ }^{2}$ и команда EXPANSION

${ }^{1}$ Главная (Пулковская) астрономическая обсерватория РАН,

${ }^{2}$ Санкт-Петербургский государственный университет

Представлены результаты однородной обработки более тысячи кривых блеска экзопланетных прохождений для 17 экзопланет.

\title{
WASP-12 b AND WASP-4 b: PLANETS FALLING ONTO THE HOST STAR?
}

R. V. Baluev ${ }^{1,2}$, E. N. Sokov ${ }^{1,2}$, I. A. Sokova ${ }^{1,2}$, V. Sh. Shaidulin ${ }^{2}$, and EXPANSION team

${ }^{1}$ Central Astronomical Observatory at Pulkovo of RAS, ${ }^{2}$ Saint Petersburg State University

We present results of a homogeneous analysis of more than thousand transit lightcurves of 17 exoplanets.

Однородным способом нами обработано $\sim 3.2 \times 10^{5}$ фотометрических измерений для $\sim 1100$ кривых блеска экзопланетных прохождений для 17 экзопланет. Фотометрические данные покрывают 16 лет (2004-2019) и включают любительские и профессиональные наблюдения. Старые архивные кривые блеска переобработаны с использованием современных экзопланетных параметров и эмпирически исправленных моделей эффекта потемнения к краю. Также проводился самосогласованный анализ прохождений и лучевых скоростей для 13 объектов.

Мы подтверждаем наличие значимого нелинейного TTV-тренда y WASP-12 без существенных поправок к его величине. Однако доплеровские данные обнаружили лучевое ускорение звезды около $(-7.5 \pm 2.2)$ м/с/год, что указывает на присутствие в системе других темных спутников помимо известной планеты b. Это предполагает,

(c) Балуев Р. В., Соков Е. Н., Сокова И. А., Шайдулин В. Ш. и команда EXPANSION, 2020 
что около 10 \% наблюдаемого TTV-сигнала возникло по причине эффекта конечности скорости света и гравитационного смещения центра масс звезды и внутренней планеты под действием невидимых тел (эффект Рёмера). Остальная часть тренда по-прежнему объясняется приливным взаимодействием планеты b со звездой.

Для WASP-4 аналогичный TTV тренд, ранее заподозренный по наблюдениям KA TESS, получился несогласованным и модельно зависимым. Он не подтверждается по результатам нашей однородной обработки, включавшей в том числе 10 новых кривых блеска, полученных наземной сетью телескопов EXPANSION в 2018 г. одновременно с TESS. Даже если TTV тренд сам по себе существует, его величину и физическую природу нельзя определить надежно. Доплеровские данные не в состоянии исключить возможность эффекта Рёмера от потенциальных невидимых спутников.

Работа выполнена при поддержке гранта РНФ 19-72-10023. 